\title{
Correction to: Reformulating prospect theory to become a von Neumann-Morgenstern theory
}

\author{
Jack Clark Francis ${ }^{1,2}$ (D) \\ Published online: 1 October 2020 \\ (c) Springer Science+Business Media, LLC, part of Springer Nature 2020
}

\section{Correction to: Review of Quantitative Finance and Accounting https://doi.org/10.1007/s11156-020-00915-8}

The authors regret the following errors occurred in the original publication of the article. The corrected text has been presented with this erratum.

In Introduction section, the paragraph above and below Figure 1 has all 8 section numbers which are mis-numbered in the text. The corrected paragraph has given below.

Section 2 provides a review of literature. Every research item discussed supports KT's prospect theory, the vNM cube root utility function, and the other vNM qualified radical utility functions, because they are all economically similar. Section 3 dichotomizes various utility functions into two groups: functions that are qualified to analyze utility theory and functions that are unqualified. Section 4 explains why the cube root utility function is a useful utility function. Section 5 contains an initial analysis of the cube root utility function. Section 6 focuses on the gains in the concave segment (the positive line segment) of the cube root utility function. Section 7 analyzes the losses in the convex segment (the negative line segment) of the cube root utility function. Section 8 uses the Taylor Expansion to analyze the decision-maker's skewness preferences. Section 9 contains summary and concluding remarks. The "Appendix" generalizes the cube root results discussed in this paper to other vNM radical utility functions.

In footnote 23, replace the first author name "Justin" with "Birru" so footnote 23 reads: "Birru and Wang (2016)."

In Section 4, the last sentence in the first paragraph should have the letter "s" added to the end of the word "circumstance" so it reads: "If circumstances arise in which..."

In Section 5, the three equations numbered Eq. (1), (1a) and (2) should all be aligned vertically on their equal signs. The corrected equations are given below.

The original article can be found online at https://doi.org/10.1007/s11156-020-00915-8.

Jack Clark Francis

jack@jcfrancis.com

1 Zicklin School of Business, Bernard Baruch College, City University of New York (CUNY), One Bernard Baruch Way, New York, NY 10010, USA

2 Stamford, CT, USA 


$$
\begin{aligned}
& U(x)=\sqrt[3]{x}=x^{\frac{1}{3}} \\
& =\left\{\begin{array}{l}
\alpha_{1} x^{\gamma_{1}}, x \geq 0, \alpha_{1}=1, \gamma_{1}=1 / 3 \\
\alpha_{2} x^{\gamma_{2}}, x<0, \alpha_{2}=1, \gamma_{2}=1 / 3
\end{array}\right. \\
& =\left\{\begin{array}{l}
x^{1 / 3} \\
-(-x)^{1 / 3}
\end{array}\right.
\end{aligned}
$$

In Section 6, the sentence above Eq. (3) should read, The exponent in Eq. (1a) is set equal to $1 / 3$ to create Eq. (3). (Footnote 35 )".

The correct reference is listed below.

\section{Reference}

Birru J, Wang B (2016) Nominal price illusion. J Financ Econ 119(3):578-598

Publisher's Note Springer Nature remains neutral with regard to jurisdictional claims in published maps and institutional affiliations. 